\title{
Entre a Afeição e o Medo, entre o Laço e a Perda: Uma Leitura da Geopoética em Sophia de Mello Breyner Andresen nos seus Contos Exemplares
}

\section{Márcia Manir Feitosa \\ Universidade Federal do Maranhão}

\begin{abstract}
Resumo: Propõe-se com este ensaio uma leitura do livro Contos exemplares, de Sophia de Mello Breyner Andresen, publicado em 1962, sob o viés da Geografia Humanista Cultural, de fundo fenomenológico, dada a relação singular com o espaço topofilico e topofóbico, além da presença antológica do mar enquanto metáfora viva da lírica de Sophia. A reflexão crítica recairá sobre três dos setes contos que compõem a obra: “A viagem”, "Praia" e "Homero", visto configurarem o paradigma estético e moral que caracteriza semelhante produção da escritora portuguesa.
\end{abstract}

Palavras-chave: Espaço, Contos exemplares, Fenomenologia

\begin{abstract}
This essay proposes a reading of the book Contos exemplars by Sophia de Mello Breyner Andresen, published in 1962 under the light of the Cultural Humanistic Geography of phenomenological background given the singular relationship between topophilic and topophobic space, besides the anthological presence of the sea as a living Sophia's lyrical metaphor. The critical reflection will fall under three of the seven short stories that make up the book: "A viagem", "Praia" e "Homero", as they set up the aesthetical paradigm that characterizes the similar production of this Portuguese writer.
\end{abstract}

Keywords: Space, Contos exemplars, Phenomenology 


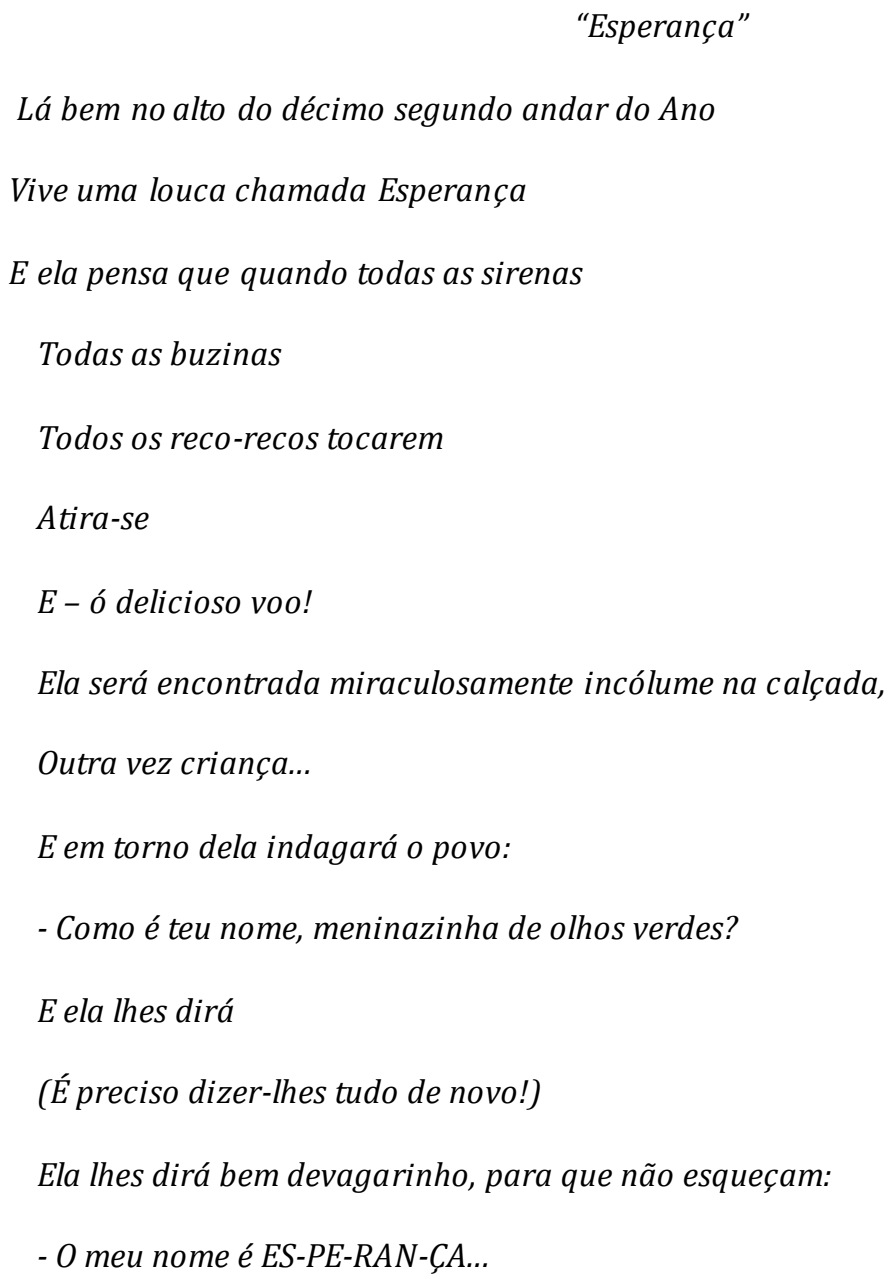

Mário Quintana

\section{Introdução}

Reconhecida, internacionalmente, como uma das poetas de maior notoriedade de Portugal e do universo da língua portuguesa, Sophia de Mello Breyner Andresen surpreende o leitor quando publica, em 1962, a coletânea de contos intitulada Contos exemplares, em que invoca a obra homônima de Cervantes - Novelas Ejemplares - para tratar da questão da moralidade sob um ponto de vista bastante pessoal.

O projeto do livro nasceu no coração da ditadura salazarista, mergulhada numa estrutura piramidal que oprimia a ascensão das classes sociais mais baixas. Não apenas por 
esse motivo, mas pelo fato de o governo propalar que a sua ideologia política se fundamentava na doutrina católica, portanto cristã. Sophia, declaradamente ofendida em seus princípios cristãos, decide por revelar, por meio de personagens verossímeis, o quão distante da religião católica está a sociedade portuguesa a partir de seus próprios defeitos, estampados em atitudes que contradizem, sobretudo, o segundo mandamento do Evangelho: o amor ao próximo.

Composto por sete contos: "O jantar do bispo", “A viagem”, Retrato de Mónica”, "Praia”, "Homero", “O homem” e "Os três reis do oriente”, o livro de Sophia parece veicular a totalidade da vida moral, na medida em que acrescenta às três virtudes teologais - fé, esperança e caridade - as quatro virtudes cardeais - a prudência, a temperança, a justiça e a força. Dentre os sete interessa-nos, particularmente, três deles, em que podemos vislumbrar não um cenário maniqueísta, em que prepondera a disputa entre o Bem e o Mal, mas um testemunho de perda em que não se torna impossível um laivo de esperança. Estamos a falar de "A viagem", "Praia" e "Homero". Nesse último conto, especialmente, a esperança é a virtude exemplar, alcançada pela palavra no mais íntimo do ser.

Interessa-nos para esse estudo uma abordagem geopoética - a poética da geografia do lugar, quando os lugares (a Terra) têm capacidade de provocar no indivíduo uma experiência estética. Assim tanto a relação singular com o espaço, ora topofilico, ora topofóbico, quanto a presença messiânica do mar, metáfora viva da lírica de Sophia serão analisados à luz dos pressupostos teóricos da Geografia Humanista Cultural, de base fenomenológica. Semelhante reflexão crítica se configurará importante no sentido de compor um panorama singular do paradigma estético e moral da autora portuguesa em seus Contos exemplares.

\section{Entre a afeição e o medo, entre o laço e a perda}

Imbuída de valores éticos como a liberdade e a justiça, em especial durante os tempos vividos antes do 25 de abril, como bem destaca Helena Buescu (2005), Sophia buscará vivê-los em sua dimensão estética ao fundir no poema a beleza e os princípios 
morais. Parafraseando as palavras da autora no momento da entrega do Grande Prémio de Poesia à obra Livro Sexto, em 1964, Helena Buescu explicita que

assim como a "maçã vermelha" é bela pelo seu rigor concreto contra o mar, dentro do quarto, em cima da mesa, também o poema será belo numa sua forma justa, que obriga ao reconhecimento da beleza serena dos valores éticos que manifesta através da componente estética que realiza. Uma beleza serena que, precisamente por isso, se pode revoltar contra o caos do "sofrimento das coisas" - e ambas estão lá, nas palavras que o poema constrói e partilha om os outros. (Buescu 2005: 51)

O que podemos evidenciar é que dos vários tipos de discurso decorrentes da pena de Sophia escorre o veio ético e poético, a matizar a forma e o conteúdo de seus versos e, no contexto em análise, as linhas de sua contística. A começar pelo conto "A viagem".

Construído de modo alegórico, o segundo conto de Contos exemplares é permeado de irreversibilidades, na medida mesma da perda constante do que se coloca como dado. Os personagens anônimos - um homem e uma mulher - anseiam por um lugar apenas conhecido pelo nome e pelo mapa, fruto de uma concepção tradicional do maravilho so. À proporção que avançam a sua procura, perdem o que ficou para trás: pessoas, objetos, paisagens, lugares, a estrada. Mas, em meio a cada "encruzilhada", vivenciam plenamente aquilo que buscam num futuro mais próximo, sem se darem conta disso.

Curiosamente, portanto, o narrador vai tecendo indícios do que poderia ser o "paraíso", desde a descrição da manhã de setembro quando o casal se aventura pela estrada em que "todas as coisas pareciam acesas" até o decorrer do dia quando usufruem de tudo que se revela efêmero. A cada momento vivido com intensidade deriva a morte para que o momento seguinte seja desfrutado.

Um sentimento intenso de apego ao ambiente natural é urdido ao longo da trajetória de ambos que sonham com uma casa silenciosa, rodeada por um jardim verde cheio de rosas por onde passaria um rio "claro, brilhante, transparente". Sonho que ofusca o presente, onde se recusam a desfrutar profundamente a vida. 0 narrador, ao relatar o anseio da mulher, insiste na repetição do advérbio "ali”, como a projetar para longe a realização do desejo: 
E ela imaginou com sede a água clara e fria em roda dos seus ombros, e imaginou a relva onde se deitariam os dois, lado a lado, à sombra das folhagens e dos frutos. Ali parariam. Ali haveria tempo para poisar os olhos nas coisas. Ali haveria tempo para tocar as coisas. Ali poderiam respirar devagar o perfume das roseiras. Ali tudo seria demora e presença. Ali haveria silêncio para escutar o murmúrio claro do rio. Silêncio para dizer as graves e puras palavras pesadas de paz e de alegria. Ali nada faltaria: o desejo seria estar ali. (Andresen 2014: 107-108)

O futuro do pretérito também atesta a ideia temporal com sentido no futuro, porém com foco no passado. Logo, imaginar tendo os olhos adiante, bêbados do que poderia advir assim que chegassem ao lugar da promessa.

A projeção do desejo de se atingir tal lugar encontra referência no geógrafo humanista Yi-Fu Tuan quando objetiva tratar do que nomeia como "topofilia". Antes de mais nada, reconhece que é um neologismo que se dirige aos laços afetivos que os seres humanos nutrem pelo ambiente natural. 0 mais interessante desse conceito é o que Tuan sustenta em seguida e que se reflete diretamente no sentimento alimentado pelos personagens, sobretudo a mulher. Assim, segundo o geógrafo chinês, esses laços divergem em termos de sutileza, intensidade e modo de expressão. E continua:

A resposta ao meio ambiente pode ser basicamente estética: em seguida, pode variar do efêmero prazer que se tem de uma vista, até a sensação de beleza, igualmente fugaz, mas muito mais intensa, que é subitamente revelada. A resposta pode será tátil: o deleite ao sentir o ar, água, terra. Mais permanentes e mais difíceis de expressar são sentimentos que temos para com um lugar, por ser o lar, o locus de reminiscências e o meio de ganhar a vida.

A topofilia não é a emoção mais forte. Quando é irresistível, podemos estar certos de que o lugar ou o meio ambiente é o veículo de acontecimentos emocionalmente fortes ou é percebido como um símbolo. (Tuan 2012: 136)

O que podemos depreender em relação ao sonho idealizado pela mulher é que não se trata de um sentimento de deleite ou de retorno às origens, antes se configura uma emoção que transcende qualquer sensação de beleza estética e se arvora à condição de símbolo. Podemos considerar essa condição na medida em que nada impede o casal de recuar ou de 
repensar a viagem a partir dos acontecimentos que se desencadeiam e que des embocam na perda, inclusive, da estrada e do próprio carro. Apesar do medo que os acomete, são impelidos ao "símbolo" que representa a viagem e o descortinar do que pensam ser o paraíso.

Cegos para o presente e para o momento vivido, rumam sempre em direção do que não poderão ter até culminarem no abismo. Vale ressaltar o quanto este conto de Sophia dialoga com a Epístola Universal de Tiago para quem é presunçoso todo aquele que se gloria com o que pode realizar no futuro. Segundo o "servo de Deus e do Senhor Jesus Cristo", como assim se apresenta no Prefácio e Saudação, o homem não sabe o que lhe acontecerá amanhã, porque a sua vida "é um vapor que aparece um pouco, e depois se desvanece" (Tg 4: 14). Mesmo diante das evidências de que deveriam aproveitar o momento (carpe diem), insistem em colocar à frente a razão que os impele para a viagem sem volta.

Entretanto, Sophia não cria um conto apocalíptico por princípio. Estrutura a narrativa de modo que seja revelada ao casal protagonista, a cada acontecimento inesperado, uma possibilidade de realização do sonho. Na verdade, impregna a narrativa de momentos epifânicos interpretados pelo casal como situações lúdicas ou instantes venturosos em face das constantes tribulações. É o caso da fonte - primeiro sinal epifânico da felicidade, indicada pelo cavador à mulher que tinha sede: "A fonte caía do alto e espetava-se na terra, direita, limpa e brilhante como uma espada. Ali beberam e ficaram com a cara e os cabelos todos salpicados de gotas, riram da alegria na frescura da água, esqueceram o cansaço, o caminho perdido, a viagem" (idem: 110). Novamente o advérbio de lugar "ali" é suscitado, agora não mais acompanhado de verbos no futuro do pretérito, mas de ações no pretérito perfeito, devidamente experienciadas.

Sabemos o quão rica é a simbologia associada à fonte. Do ponto de vista cristão, dada a mensagem moral e evangélica de Sophia, simbolizaria a água e o sangue do Cristo que brotaram de Suas chagas e que depois teriam sido recolhidos no Graal por José de Arimateia (Chevalier/Gheerbrant 1995). Equivaleria à imortalidade, haja vista a sua busca pelos cavaleiros arturianos representados por Galaaz. 
Saciada a sede, não há como retomar o que foi deixado para trás, nem ainda a fonte, perdida no instante mesmo em que almejaram dar continuidade à viagem. Diante do cansaço da mulher, o homem argumenta com a esperança pela terra prometida: "- Quando chegarmos à terra para onde vamos, descansarás, este ndida na relva, à sombra das árvores e dos frutos" (idem: 112).

Abandonada a fonte, surge novo momento epifânico, representado pela pequena casa de camponeses vazia, onde, em cima de uma mesa, oferecia-se o vinho e o pão cristãos. Saciada, portanto, a fome, retomam a estrada que, surpreendentemente, desaparece. 0 retorno a casa é em vão. 0 medo se sobrepõe e se instaura um lampejo de lucidez na mulher: Por que continuar se tudo o que se encontra se perde? Ainda assim avançam e deparam com outro símbolo místico: a macieira. De acordo com Chevalier e Gheerbrant (1995: 772), "a maçã é simbolicamente utilizada em diversos sentidos aparentemente distintos, mas que mais ou menos se aproximam. (...). Trata-se, em todas as circunstâncias, de um meio de conhecimento..." Tanto do conhecimento unificador que confere a imortalidade, quanto o conhecimento desagregador que incita a queda.

Embora o dia estivesse cheio de luz, em que "todas as coisas pareciam acesas", o casal se despede da felicidade encontrada em prol da incerteza do caminho. Não adiantou terem avistado um tarro de cortiça e uma bilha de barro junto de uma sebe e depois disso terem também avistado um regato onde puderam matar a sede. Não se valem da experiência adquirida diante de tantas perdas, e mais uma vez perdem o que se reveste de significado epifânico.

Tuan, em Espaço e lugar: a perspectiva da experiência, explicita que "a experiência implica a capacidade de aprender a partir da própria vivência". Assim, "esperienciar", segundo o geógrafo, "é aprender; significa atuar sobre o dado e criar a partir dele. 0 dado não pode ser conhecido em sua essência. 0 que pode ser conhecido é uma realidade que é um constructo da experiência, uma criação de sentimento e pensamento" (Tuan 2013: 18). O homem e a mulher se recusam a aprender com a experiência, valendo-se tão somente do pensamento que os impele para o distanciamento da felicidade plena. 
Dando sequência à caminhada não mais pela estrada - agora inexistente -, antes pelo carreiro, deparam-se com uma grande floresta por onde passavam "grandes raios de luz oblíqua" e onde "o ar era verde e doirado". Sentem-se maravilhados diante de tanta beleza e frescor e, apesar do desaparecimento de um lenhador com quem antes tinham conversado, se dispõem a ouvir a terra e a desfrutarem de uma sebe carregada de amoras. Com o pensamento fixo na terra prometida pelo mapa, abandonam novamente o mais recente momento epifânico, mas com uma diferença: levam consigo uma considerável quantidade de amoras dentro do lenço que é cuidadosamente atado em suas quatro pontas. Ao que parece, a experiência da perda constante despertou, principalmente na mulher, a tentativa de manutenção de um estado de segurança. Não só: ela se predispõe a vivenciar o ambiente natural da floresta como se não estivesse perdida. Antecipa cada enunciação de suas sensações ao homem com uma conjunção concessiva, de modo a fazer uma ressalva em face do objetivo principal: chegarem ao lugar planejado. Estão alegres sim, mas ainda não atingiram a felicidade ansiada:

-Ah! - disse ela -, mesmo perdida, vejo como tudo é perfumado e belo. Mesmo sem saber se jamais chegarei, apetece-me rir e cantar em honra da beleza das coisas. Mesmo neste caminho que eu não sei onde leva, as árvores são verdes e frescas como se as alimentasse uma certeza profunda. Mesmo aqui a luz poisa leve nos nossos rostos como se nos reconhecesse. Estou cheia de medo e estou alegre. (idem: 121-122)

Tanto a amoreira quanto a floresta detêm significativa carga simbólica no conto, a exemplo da macieira e da fonte. Na China antiga, acentuam Chevalier e Gheerbrant (1995: 48), "a amoreira é a árvore do levante. É a residência da Mãe dos sóis e a árvore através da qual se eleva o Sol nascente". Já a floresta é tida como santuário para os celtas, como um templo para os japoneses e chineses, sendo mais ambivalente para os poetas a quem desperta angústia e serenidade, opressão e simpatia. Para a psicanálise e, particularmente, para Jung, a floresta simboliza o lado inconsciente, visto seu denso enraizamento e obscuridade excessiva. No conto de Sophia, a chegada à floresta é acompanhada da luz do sol que irradia seus raios sobre os rostos dos personagens, contagiando -os com sua beleza e 
o "ar doirado e verde". Nela foi possível colher amoras e desfrutar do seu sabor e aroma. Nela ainda foi possível vislumbrar um rio e mergulhar em suas águas limpas, cercadas por flores selvagens. Nesse ambiente de paz interior e aura paradisíaca, o casal parece vivenciar o sonho alimentado páginas atrás quando se propuseram a perseguir o lugar idílico de suas vidas. Dizemos "parece" em face da seguinte observação da mulher: "- Aqui é quase como a terra para onde vamos". Merece destaque o emprego do advérbio "aqui" que se contrapõe ao "ali" insistentemente demarcado em situações anteriores, como a assumir a conquista do desejo ansiado. No entanto, existe o "quase" que imprime a dúvida e impele ambos a retomarem a caminhada para a terra desconhecida. A predicação "aqui é um lugar de passagem", expressa pelo homem, associa a floresta a um espaço de transição, a um divisor de águas o qual deveriam transpor.

Ainda que a mulher tentasse criar laços com a floresta ao arrancar flores da terra com a raiz, o parceiro a induz a seguir adiante, adentrando o pôr-do-sol e, consequentemente, a noite. Fecha-se, assim, o ciclo do dia e das oportunidades epifânicas de alcançar a felicidade.

Após o clímax típico de um conto tradicional, “A viagem” encerra a sua trajetória com um desfecho trágico e inevitável, à sombra do crepúsculo e ao nascimento iminente da Lua. Da felicidade plena na floresta decorre a queda no abismo, "poço da escuridão" e "mundo das profundezas ou das alturas indefinidas", onde ambos irão desfrutar da infelicidade. Apesar da tentativa sôfrega da mulher de se salvar, "viu que, quando as raízes se rompessem, não se poderia agarrar a nada, nem mesmo a si própria. Pois era ela pró pria o que ela agora ia perder" (idem: 129). 0 mais surpreendente é a incapacidade de aceitar a situação até os últimos instantes, haja vista a certeza de que, para além do abismo, haveria alguém a salvá-la. 0 chamamento do futuro suplanta o presente.

Já nos contos "Praia" e "Homero", o que podemos evidenciar é a presença crucial do mar, considerado para Sophia, como bem ressalta Federico Bertolazzi no "Prefácio" da edição da Assírio e Alvim, "um paradigma estético, poético e até ético (...), porque a sua lição de beleza contribui para a formação de um rigor formal que é paradigma da moral". (Bertolazzi 2005: 22). Contrariamente ao que ocorre em "A viagem", em "Praia", uma das 
personagens, embora se mova numa dimensão suspensa, é possível antever um sinal de esperança quando evoca o mar. Em convívio com a narradora e com outras personagens, tal homem, tão anônimo quanto os demais convivas daquele clube e daquela sala de baile, guarda o relógio do tempo e se põe à espera, "à margem do vivido". Evoca a memória sebastianista, tão cara a Sophia, sobretudo quando do aparecimento do nevoeiro, representação clássica da figura de D. Sebastião. Nevoeiro: "Símbolo do indeterminado, de uma fase da evolução", como bem ressaltam Chevalier e Gheerbrant (1995: 634), "quando as formas não se distinguem ainda, ou quando as formas antigas que estão desaparecendo ainda não foram substituídas por formas novas precisas".

Em meio à Segunda Guerra Mundial, quando da invasão nazista na Europa, uma figura faz lembrar que a guerra ainda estava viva. No entanto, no instante seguinte, Rommel recuava. Curiosamente, esse recuo acontece após o "homem do relógio" ter se proposto a ouvir as notícias acerca da guerra. 0 homem do tempo, portanto, parece anunciar um tempo de paz que será transfigurado pelo nevoeiro.

Curiosamente, chama a atenção o emprego pela narradora dos cognatos referentes à palavra "lúcido". Sua primeira aparição se verifica um parágrafo antes da apresentação do homem do tempo, justamente em função da espera tão desejada: "Porque a espera, a espera das coisas fantásticas, visíveis e reais, a espera das coisas destinadas, prometidas, pressentidas, ia-se tornando quase lucidamente alucinada" (idem: 147). 0 segundo emprego nasce da fértil imaginação da narradora, embebida com a notícia da capitulação nazista no deserto: “Tentei imaginar as sombras e a doçura das areias, o brilho lucidíssimo das estrelas, (...). Os homens: lucidamente vencidos, (...) Lucidamente vencidos, combatendo sob o brilho lucidíssimo dos astros" (idem: 152).

A insistência com a ideia de lucidez atinge o clímax no momento em que o nevoeiro transfigura tudo e o ambiente se vê invadido exclusivamente pela voz do mar. 0 único a transpirar resplandescência e luz. Para o geógrafo francês Eric Dardel, "o mar é uma força envolvente, ambiência em seu sentido mais apropriado; ele é um elemento" (Dardel 2011: 21). Em consonância com o conto, Dardel acentua que "a batida regular das vagas, o balanço muito lento das marés, o escoamento das águas correntes temporalizam o mundo e fazem 
aparecer o tempo como matéria da existência,...” (idem: 22). Mar e destino entrelaçados, portanto.

É o que nutre o conto "Homero", o único que, na perspectiva de Bertolazzi, torna possível a realização da esperança. Narrado também na primeira pessoa por uma personagem feminina, tem como protagonista outro homem, conhecido por Búzio, em que "tudo nele lembrava coisas marítimas", a começar pelo nome:

A sua barba branca e ondulada era igual a uma onda de espuma. As grossas veias azuis das suas pernas eram iguais a cabos de navio. 0 seu corpo parecia um mastro e seu andar era baloiçado como o andar dum marinheiro ou dum barco. Os seus olhos, como o próprio mar, ora eram azuis, ora cinzentos, ora verdes, e às vezes mesmo os vi roxos. E trazia sempre na mão direita duas conchas. (idem: 157)

De posse de um cajado que servia ao mesmo tempo de apoio e de arma contra o ataque de cães raivosos, Búzio se sustinha com nacos de pão e alguns tostões que guardava em um saco de chita remendada e severamente desbotada pelo sol. Sempre que apontava o dia, Búzio, antecedido pelo seu cão velho e sujo, entoava, com o toque das castanholas de conchas, sua longa melopeia ritmada por meio da qual recebia os nacos de pão e os tostões. Entretanto, diferentemente dos outros desvalidos sempre queixosos e em um murmúrio incansável de gemidos, Búzio não aparecia ferido, nem despertava a comiseração, antes se revelava imbricado com a natureza: “o Búzio não possuía nada, como uma árvore não possui nada. Vivia com a terra toda que era ele próprio. A ter ra era sua mãe e sua mulher, sua casa e sua companhia, sua cama, seu alimento, seu destino e sua vida" (idem: 160). Búzio era a paisagem, na acepção que lhe confere Dardel sob o ponto de vista fenomenológico:

A paisagem não é um círculo fechado, mas um desdobramento. Ela não é verdadeiramente geográfica a não ser pelo fundo, real ou imaginário, que o espaço abre além do olhar. [ ] ...é um escape para toda a Terra, uma janela sobre as possibilidades ilimitadas: um horizonte. Não uma linha fixa, mas um movimento, um impulso. (idem: 31) 
Em sua ligação existencial com a Terra, Búzio nutre pela natureza um sentimento lúcido que afeta a carne e o sangue. Semelhante sentimento contagia a narradora que se põe a segui-lo logo após ele ter chegado a sua casa à beira da praia. Em meio a uma duna, erguia-se o porte alto e direito do Búzio que se confundia com a tarde à espera do ocaso, a discursar com o mar "palavras moduladas como um canto, palavras quase visíveis que ocupavam os espaços do ar com a sua forma, a sua densidade e o seu peso" (idem: 163-164). Com suas palavras brilhantes, Búzio nomeava a vida ao mesmo tempo que a invocava. Divinamente, ele comungava a íntima relação do Homem com a Terra por meio da palavra. Travestida de poesia, a palavra de Homero inunda de esperança a literatura de Sophia com sua nudez plena e inteira, capaz de sugerir a felicidade ansiada simplesmente pelo esplendor da presença das coisas.

O gesto exemplar, portanto, que constitui o fio condutor a que Sophia pretende chegar se revela em termos metalinguísticos. A epifania verdadeira é a palavra.

\section{Considerações finais}

Dos contos analisados do livro Contos exemplares foi possível evidenciar, ao lado da experiência estética inerente à pena de Sophia, a presença da esperança como a virtude exemplar a ser perseguida pelos personagens, haja vista o comportamento lírico do Búzio do conto "Homero" na sua relação divina com a Terra.

À luz dos pressupostos teóricos da Geografia Humanista Cultural, descortinamos a íntima vinculação do conto "A viagem" com o espaço topofílico ou topofóbico, em que afloram ou a afeição e o laço, ou o medo e a perda. Em "Praia" e "Homero", o que pudemos destacar é o afloramento do mar enquanto metáfora viva a dominar o espaço das narrativas. Ao lado, portanto, da perspectiva espacial ganham destaque os princípios éticos de tom moralizante, a veicularem o Evangelho de Cristo e o seu mandamento fundamental: o amor ao próximo.

Ao ter suscitado como epígrafe um trecho do "Prólogo al Lector" das Novelas Ejemplares, de Cervantes, Sophia procurou arrebatar seu leitor para a condição da exemplaridade, para a fagulha divina que há nas criaturas ainda que delas nada se espere. 
Sob o manto da beleza e do encanto pela palavra, Contos exemplares inspira o Bem maior numa sociedade marcada pelo véu da ditadura e pela ausência de liberdade.

\section{Bibliografia}

A BÍBLIA SAGRADA (1995), trad. João Ferreira de Almeida, São Paulo, Sociedade Bíblica Trinitariana do Brasil.

Andresen, Sophia de Mello Breyner (2014), Contos exemplares, 39a ed., Porto, Assírio \& Alvim.

Bertolazzi, Federico, Prefácio, in: Andresen, Sophia de Mello Breyner (2014), Contos exemplares, 39aㅡ ed., Porto, Assirio \& Alvim.

Buescu, Helena Carvalhão (2005), Cristalizações: fronteiras da modernidade, Lisboa, Relógio d'Água Editores.

Cervantes, Miguel de (2013), Novelas ejemplares, edición, estúdio y notas de Jorge Garcia Lópes, Madrid, Real Academia Española - Barcelona, Galaxia Gutenberg - Círculo de Lectores.

Chevalier, Jean/ Gheerbrant, Alain (1995), Dicionário de símbolos, trad. Vera da Costa e Silva et al, Rio de Janeiro, José Olympio.

Dardel, Eric (2011), O Homem e a Terra: natureza da realidade geográfica, trad. Werther Holzer, São Paulo, Perspectiva.

Quintana, Mário (1998), Nova antologia poética, São Paulo, Editora Globo. 
Tuan, Yi-Fu (2012), Topofilia: um estudo da percepção, atitudes e valores do meio ambiente, trad. Lívia de Oliveira, Londrina: EDUEL.

-- (2013), Espaço e lugar: a perspectiva da experiência, trad. Lívia de Oliveira. Londrina: EDUEL.

Márcia Manir Feitosa é Mestre e Doutora em Literatura Portuguesa pela Universidade de São Paulo/Brasil. Pós-Doutora em Estudos Comparatistas pela Universidade de Lisboa. Profa. Titular da Universidade Federal do Maranhão/Brasil. Docente permanente dos Programas de Pós-Graduação em Letras e em Cultura e Sociedade da Universidade Federal do Maranhão/Brasil. Autora do livro Fernando Pessoa e Omar Khayyam: o Ruba'iyat na poesia portuguesa do século XX (1998). Organizadora, juntamente com a Profa. Ida Ferreira Alves, da Universidade Federal Fluminense/Brasil, do livro Literatura e paisagem: perspectivas e diálogos (2010). 